\title{
ASSESSING THE SUITABILITY OF TURMERIC SEED RHIZOME SIZES ON BIOMETRIC AND QUALITATIVE TRAITS UNDER MID HILL CONDITIONS
}

\author{
T. Angami ${ }^{1}$, H. Kalita ${ }^{1}$, L. Touthang ${ }^{1}$, A. Chandra ${ }^{1}$, H. L. Devi ${ }^{2}$, \\ S. Baruah ${ }^{1}$, B. Bam ${ }^{1}$ and A. Khatoon ${ }^{1}$ \\ ${ }^{1}$ ICAR Research Complex_for NEH Region, A.P Centre, Basar - 791 101, West Siang District, Arunachal Pradesh \\ ${ }^{2}$ ICAR Research Complex for NEH Region, Tripura Centre, Lembucherra -799 210, West Tripura
}

Received - June 18, 2017; Revision - Septermber 27, 2017; Accepted - October 21, 2017

Available Online - October 31, 2017

http://dx.doi.org/10.18006/2017.5(5).631.635

KEYWORDS
Turmeric
Mother rhizome
Finger rhizome
Growth, Yield
Quality
Curcumin
Oleoresin

\begin{abstract}
A field experiment was carried out with the objectives to evaluate and assess the suitability of Turmeric seed rhizome sizes under mid hill conditions of Arunachal Pradesh. The experiment consisted seven treatments of different grades of Turmeric rhizome var. Megha Turmeric-1. The results of study revealed that heavier the mother rhizome, gave better plant growth characteristics. Further it was reported that use of 50-60 g mother rhizome as a planting material resulted in maximum in case of all biometric characteristics with a plant height $(121.33 \mathrm{~cm})$, leaf size of length $(62.79 \mathrm{~cm})$, breadth $(18.05$ $\mathrm{cm})$, number of leaves per plant (7.33), number of tillers per plant $(4.24)$, and stem girth $(2.20 \mathrm{~cm})$ which were significantly higher as compared to the treatments with smaller rhizomes. As far as fresh and dried rhizome yields are concerned, mother rhizomes (50-60 g) yielded maximum fresh rhizome (24.58 t/ha) and dried rhizome yield (4.79 t/ha) which reduced considerably with small seed size. Curcumin and oleoresin, an important biochemical property in turmeric were also exhibited maximum in terms of percent and yield when mother rhizome was 50-60 g used as planting material and this amount is followed by mother rhizome $(30-40 \mathrm{~g})$.
\end{abstract}

* Corresponding author

E-mail: tthejaangami@yahoo.com (T. Angami)

Peer review under responsibility of Journal of Experimental Biology and Agricultural Sciences.

Production and Hosting by Horizon Publisher India [HPI] (http://www.horizonpublisherindia.in/).

All rights reserved.
All the article published by Journal of Experimental Biology and Agricultural Sciences is licensed under a Creative Commons Attribution-NonCommercial 4.0 International License Based on a work at www.jebas.org.

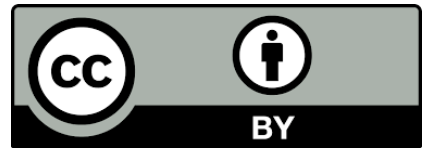




\section{Introduction}

Turmeric (Curcuma longa L.) belonging to the family Zingiberaceae and cultivated extensively not only in India but also in other Southeast Asian countries. India is the largest producer, consumer and exporter (approximately 90\%) of turmeric in the world (Anandaraj et al., 2014). It is one of the extensively used spices and colouring agents especially in the Indian subcontinent (Sarker \& Nahar, 2007). Turmeric is prized and valued for its ability to impart brilliant yellow-gold colour to food due to the presence of secondary metabolite (yellow pigment) i.e. curcumin (Rakhunde et al., 1998) and is considered as an important factor in sensory and consumer acceptance of products (Wang et al., 2009). Besides being a spice crop, it has worldwide demand in cosmetic as well as in medicinal industry (Hossain et al., 2005). Its role as an antimalarial (Nandakumar et al., 2006), anti-inflammatory and antitumor (Gupta et al., 2012) has been well appreciated worldwide and it has also been known to modulate lipid metabolism, which has been implicated in obesity (Alappat \& Awad, 2010). Normally turmeric is propagated through a small portion of rhizomes known as seed rhizome which gives the economic yield (Ravindran et al., 2005). So it is obvious that the selection of right size planting material (length, weight and number of growing buds per seed) is an important factor for turmeric cultivation. Although the standard size of turmeric rhizome for planting is $20-30 \mathrm{~g}$ as per the scientific package of practices yet many researchers reported that planting larger turmeric seed rhizomes resulted in higher yield compared to smaller seed rhizomes (Randhawa \& Mishra, 1974; Borget, 1993; Hossain et al., 2005). Further, Awasthy \& Jessykutty (2017) also reported that a turmeric rhizome bit of approximate weight i.e. $7 \mathrm{~g}$ with 3 node recorded the highest sprouting percentage with good morphological characteristics.

Therefore, in order to assess the suitability of the variety Megha Turmeric-1 seed rhizome sizes based on its important biometric characteristics and quality attributes, a preliminary investigation was carried out with the objectives to study the growth, yield and quality as influenced by different grades of turmeric seed rhizomes so as to identify the best rhizome size that could be used as planting material under mid hill condition of Arunachal Pradesh.

\section{Materials and Methods}

The present investigation was carried out at ICAR Research Farm, Gori, Basar, Arunachal Pradesh, India situated in the mid hill zone at the latitude of $27^{\circ} 59.537^{\prime} \mathrm{N}$ and longitude of $94^{\circ} 41.269^{\prime} \mathrm{E}$ with an altitude of $650 \mathrm{~m}$ above sea level during March 2015 to assess the suitable seed rhizome sizes with respect to its growth, yield and quality traits. The variety grown for the study was Megha Turmeric-1 which was developed from ICAR (Research
Complex) for NEH Region, Umiam, Meghalaya through clonal selection having tolerant to leaf blotch and leaf spot with crop duration of 300-315 days. Cultivation practice was followed as per the recommended scientific package of practices. The field experiment was laid out in RBD (Randomised Block Design) with three replications having seven treatments viz., Mother rhizome (50-60 g), Mother rhizome (30-40 g), Mother rhizome (10-20 g), Finger rhizome (50-60 g), Finger rhizome (30-40 g), Finger rhizome (10-20 g), Finger rhizome ( $<10 \mathrm{~g})$. In each plot, selected plants were tagged to record biometric observations on growth and yield attributes. For curcumin content measurement, finely ground turmeric powder samples $(1 \mathrm{~g})$ were extracted by refluxing over a water-cooled condenser with $100 \mathrm{ml}$ of distilled alcohol (methanol) for $2 \frac{1}{2} 2$ hours. The extract was transferred to a $100 \mathrm{ml}$ volumetric flask and volume was made to $100 \mathrm{ml}$ with alcohol (methanol). It was then filtered and an aliquot of $2 \mathrm{ml}$ was transferred to a $25 \mathrm{ml}$ volumetric flask and made to $25 \mathrm{ml}$ volume, mixed well and the absorbance of this solution was measured at $425 \mathrm{~nm}$ wavelength against blank made of alcohol (Manjunath et al., 1991). The analysis of curcumin was replicated thrice and the mean was taken for data analysis. Per cent oleoresin was also estimated as outlined by Sadasivam \& Manickam, 2004 where ten grams of powder sample was taken in chromatographic column which was then eluted with $50 \mathrm{ml}$ of acetone. The slurry was collected in a pre-weighed beaker and solvent was allowed to evaporate. The collected slurry was cooled and weighed. Difference in weight was calculated and then converted into per cent. Data recorded on different aspects of crop were tabulated and subjected to statistical analysis as outlined by Gomez \& Gomez (1984). Significance difference between treatment means was tested through ' $F$ ' test and the critical difference (CD) was worked out wherever ' $F$ ' value was found to be significant for treatment effect. The results are presented at $5 \%$ level of significance $(\mathrm{P}=0.05)$.

\section{Results and Discussion}

\subsection{Effect of different seed rhizome sizes on biometric characteristics of turmeric}

In present study, uniform seedling emergence was observed irrespective of the size of seed rhizomes. The biometric characteristics of turmeric as influenced by different rhizome size are presented in (Table 1). The vegetative growth characteristics viz. plant height, leaf size, number of tillers, number of leaves and stem girth were recorded. Plants arising from 50-60 g mother rhizome were found healthier because larger rhizomes had larger buds and diameter. Among the different grades of rhizome used, the mother rhizome with 50-60 g recorded the highest plant height $(121.33 \mathrm{~cm})$, the reason being larger seed rhizomes contains larger amount of reserves that enhanced seedling growth, which ultimately resulted in a taller plant (Padmadevi et al., 2012). 
Table 1 Effect of different seed rhizome sizes on biometric characteristics of turmeric

\begin{tabular}{|c|c|c|c|c|c|c|}
\hline Treatments & $\begin{array}{l}\text { Plant height } \\
\quad(\mathrm{cm})\end{array}$ & $\begin{array}{l}\text { Leaf length } \\
\quad(\mathrm{cm})\end{array}$ & $\begin{array}{c}\text { Leaf } \\
\text { breadth } \\
(\mathrm{cm})\end{array}$ & $\begin{array}{c}\text { Number of } \\
\text { leaves }\end{array}$ & $\begin{array}{l}\text { Number of } \\
\text { tillers }\end{array}$ & $\begin{array}{l}\text { Stem girth } \\
(\mathrm{cm})\end{array}$ \\
\hline Mother rhizome $(50-60 \mathrm{~g})$ & 121.33 & 62.79 & 18.05 & 7.33 & 4.24 & 2.20 \\
\hline Mother rhizome $(30-40 \mathrm{~g})$ & 119.50 & 58.53 & 16.56 & 7.28 & 4.07 & 2.18 \\
\hline Mother rhizome $(10-20 \mathrm{~g})$ & 111.67 & 54.15 & 14.09 & 6.83 & 3.17 & 1.83 \\
\hline Finger rhizome (50-60 g) & 114.17 & 56.16 & 15.10 & 7.22 & 3.47 & 2.01 \\
\hline Finger rhizome $(30-40 \mathrm{~g})$ & 113.33 & 54.95 & 14.27 & 7.07 & 3.23 & 1.97 \\
\hline Finger rhizome $(10-20 \mathrm{~g})$ & 101.67 & 51.55 & 13.09 & 6.77 & 3.11 & 1.60 \\
\hline Finger rhizome $(<10 \mathrm{~g})$ & 94.67 & 50.27 & 12.22 & 6.57 & 2.68 & 1.50 \\
\hline $\mathrm{SEm} \pm$ & 1.85 & 1.22 & 0.42 & 0.16 & 0.28 & 0.13 \\
\hline $\mathrm{CD}(P=0.05)$ & 5.70 & 3.75 & 1.29 & 0.50 & 0.88 & 0.39 \\
\hline
\end{tabular}

Highest number of tillers (4.24) and leaves (7.33) per plant were also exhibited from the mother rhizome (50-60 g). The number of tillers and leaves increased as the seed size increased, because the plants from the larger seeds were longer and had a larger number of tillers. The shoot with a higher leaf number and larger leaf size received a higher solar energy for photosynthesis, which ultimately resulted in a larger shoot biomass. This results are in agreement with the report of Sarker et al. (2001). Meanwhile, the maximum stem girth $(2.20 \mathrm{~cm})$ and leaf area of length $(62.79 \mathrm{~cm})$ and breadth $(18.05 \mathrm{~cm})$ was also exhibited in mother rhizome of $50-60 \mathrm{~g}$ followed by mother rhizome of $30-40 \mathrm{~g}$.

\subsection{Effect of different seed rhizome sizes on yield of turmeric}

The weight of mother rhizomes exhibited positive and significant correlation with rhizome yield. Plants from larger seeds of mother rhizome (50-60 g) had bigger shoot base and produced a higher number of daughter rhizomes, which ultimately increased the yield of turmeric. In this experiment, 50-60 g mother rhizome recorded the best performance in fresh and dried rhizome yield (Table 2) because of sufficient food reserves which probably encouraged vigorous plant growth that should have eventually transformed into yield (Padmadevi et al., 2012). Similar results

Table 2 Effect of different seed rhizome sizes on yield and quality attributes of turmeric

\begin{tabular}{|c|c|c|c|c|}
\hline Treatments & $\begin{array}{l}\text { Fresh } \\
\text { rhizome } \\
\text { yield } \\
\text { (t/ha) }\end{array}$ & $\begin{array}{l}\text { Dried rhizome } \\
\text { yield } \\
\text { (t/ha) }\end{array}$ & $\begin{array}{c}\text { Curcumin content } \\
(\%)\end{array}$ & $\begin{array}{l}\text { Oleoresin content } \\
(\%)\end{array}$ \\
\hline Mother rhizome (50-60 g) & 24.58 & 4.79 & 6.20 & 13.53 \\
\hline Mother rhizome (30-40 g) & 23.50 & 4.58 & 6.16 & 13.20 \\
\hline Mother rhizome (10-20 g) & 21.42 & 4.18 & 6.11 & 13.03 \\
\hline Finger rhizome (50-60 g) & 22.67 & 4.42 & 6.08 & 12.47 \\
\hline Finger rhizome $(30-40 \mathrm{~g})$ & 22.50 & 4.39 & 6.03 & 12.50 \\
\hline Finger rhizome (10-20 g) & 18.29 & 3.57 & 5.25 & 11.07 \\
\hline Finger rhizome $(<10 \mathrm{~g})$ & 18.04 & 3.52 & 5.18 & 8.73 \\
\hline $\mathrm{SEm} \pm$ & 0.41 & 0.08 & 0.17 & 0.84 \\
\hline $\mathrm{CD}(P=0.05)$ & 1.25 & 0.24 & 0.52 & 2.60 \\
\hline
\end{tabular}

Journal of Experimental Biology and Agriculture Science http://www.jebas.org 
were also reported by Kumar \& Gill, (2010) who reported that increased rhizome yield in mother rhizome planting material might be attributed to better crop growth in terms of higher plant height, more number of leaves and tillers per plant which enabled more photosynthesis causing higher yields. Variation in sizes of rhizomes affects its performance as a sink (source-sink relationship). As far as the sink is concerned, mother rhizomes are better than fingers. Mother rhizomes are rich in nutrients due to better mobilization of the same. Thus, the mother rhizomes are considered as better planting material than finger rhizomes producing more vigorous plants ultimately increasing the yield. Similar findings were also recorded by Singh et al. (2000) and Alam et al. (2003).

\subsection{Effect of different seed rhizome sizes on quality attributes of turmeric}

The results presented in table 2 revealed that 50-60 g mother rhizome have highest curcumin $(6.29 \%)$ and oleoresin content $(13.53 \%)$ and this was followed by mother rhizome with $30-40 \mathrm{~g}$ and showed curcumin and oleoresin yield of $650.14 \mathrm{~kg} / \mathrm{ha}$ and $297.16 \mathrm{~kg} / \mathrm{ha}$ respectively as shown in Figure1 which might be attributed to the bigger rhizome size which has higher reserved food which enhanced better vegetative growth leading to accumulation of more photosynthates in rhizomes and production of secondary metabolites like curcumin and oleoresin. The results obtained in the present study are in conformity with the findings of Kumar et al. (1992) who reported better quality attributes using mother rhizomes of turmeric in cultivar Duggirala.

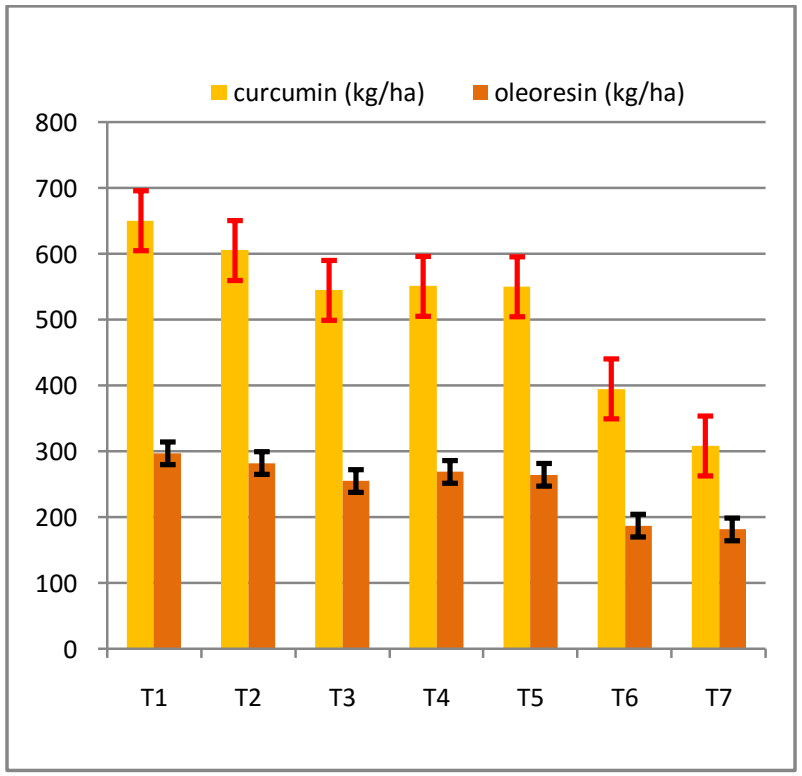

Figure 1 Curcumin and oleoresin yield as influenced by different turmeric seed rhizome sizes

\section{Conclusion}

From this experiment, it is apparent that heavier the turmeric rhizome, better the plant growth characteristics quantitatively and qualitatively. Therefore, it can be concluded that use of mother rhizome (50-60 g) of variety Megha Turmeric-1 as seed material gave the best performance in all the growth, yield and quality attributes making it a suitable rhizome size that could be used as planting material under mid hill condition of Arunachal Pradesh. However, besides the study conducted, there is need in future and scope to examine the effect of larger seed rhizome sizes (> $60 \mathrm{~g}$ ) which might result in a different response both in terms of quantity and quality.

\section{Conflict of Interest}

Authors would hereby like to declare that there is no conflict of interests that could possibly arise.

\section{References}

Alam MK, Islam Z, Rouf MA, Alam MS, Mondal HP (2003) Response of turmeric to planting material and mulching in the hilly region of Bangladesh. Pakistan Journal of Biological Science 6: 7-9.

Alappat L, Awad AB (2010) Curcumin and obesity: evidence and mechanisms. Nutrition Reviews 68: 729-738.

Anandaraj A, Prasath D, Kandiannan K, John Zachariah T, Srinivasan V, Jha AK, Singh BK, Singh AK, Pandey VP, Singh SP, Shoba N, Jana JC, Ravindra Kumar K, Uma Maheswari K (2014) Genotype by environment interaction effects on yield and curcumin in turmeric (Curcuma longa L.). Industrial Crops and Products 53: 358-364.

Awasthy TS, Jessykutty PC (2017) Rapid multiplication of Kasthuri turmeric (Curcuma aromatica Salisb.) through minisett technique and nursery management. Journal of Spices and Aromatic Crop 26: 47-50.

Borget M (1993) Spice plants. The tropical agriculturalist. MacMillan, London, United Kingdom.

Gomez KA, Gomez AA (1984) Statistical Procedures for Agricultural Research. International Rice Research Institute. John Wiley and Sons. New York. USA. Pp: 139-240.

Gupta SC, Patchva S, Koh W, Aggarwal BB (2012) Discovery of curcumin, acomponent of golden spice, and its miraculous biological activities. Clinical and Experimental Pharmacology and Physiology 39: 283-299. 
Hossain MA, Ishimine Y, Akamine H, Motomura K (2005) Effects of Seed Rhizome Size on Growth and Yield of Turmeric (Curcuma longa L.). Plant Production Science 8: 86-94.

Kumar B, Gill BS (2010) Growth, yield and quality of turmeric (Curcuma longa L.) as influenced by planting method, plant density and planting material. Journal of Spices and Aromatic Crops 19: 42-49.

Kumar GVV, Reddy KS, Rao MS, Ramavatharam N (1992) Soil and plant characters influencing curcumin content of turmeric. Indian Cocoa, Arecanut and Spices Journal 15: 102-105.

Manjunath MN, Sattigeri VD, Nagaraj KV (1991) Curcumin in turmeric. Spice India 12: 7-9.

Nandakumar DN, Nagaraj VA, Vathsala PG, Rangarajan P, Padmanaban G(2006) Curcumin-Artemisinin combination therapy for malaria. Antimicrobial Agents and Chemotherapy 50: 18591860 .

Padmadevi K, JeevaJothi L, Ponnuswami V, Durgavathi V, Rijwana Parveen I (2012) Effect of different grades of rhizomes on growth and yield of turmeric (Curcuma longa L.). The Asian Journal of Horticulture 7: 465-467.

Rakhunde SD, Munjal SV, Patil SR (1998) Curcumin and essential oil contents of some commonly grown turmeric (Curcuma longa L.) cultivars in Maharashtra. Journal of Food Science and Technology 35: 352-354.
Randhawa KS, Mishra KA (1974) Effect of sowing dates, seed size and spacing on the growth and yield of turmeric. Punjab Horticulture Journal 14: 53-55.

Ravindran PN, Nimal BK, Shiva KN (2005) Botany and crop improvement of ginger. In: Ginger: the genus Zingiberin. CRP Press. New York. Pp. 15-86.

Sadasivam S, Manickam A (2004) Biochemical methods for agricultural sciences. Wiley Eastern Limited.New Delhi. pp. 178192.

Sarker MAZ, Murayama S, Ishimine Y, Nakamura I (2001) Physio morphological characters of F1 hybrids of rice (Oryza sativa L.) in Japonica India crosses. II. Heterosis for leaf area and dry matter accumulation. Plant Production Science 4: 202-209.

Sarker SD, Nahar L (2007) Bioactivity of Turmeric in Turmeric: The Genus Curcuma. Taylor and Francis Group.LLC. Pp. 258285.

Singh J, Malik YS, Nehra BK, Partap PS (2000) Effect of size of seed rhizomes and plant spacing on growth and yield of turmeric (Curcuma longa L.). Haryana Journal of Horticultural Science 29: 258-260.

Wang Y, Lu Z, Lv F, Xiaomei B (2009) Study on microencapsulation of curcumin pigments by spray drying. European Food Research and Technology 229:391-396. 